\title{
Effect of skeletal muscle demand on cardiovascular function
}

\author{
CRAIG A. HARMS \\ Department of Kinesiology, Kansas State University, Manhattan, KS 66506
}

\begin{abstract}
HARMS, C. A. Effect of skeletal muscle demand on cardiovascular function. Med. Sci. Sports Exerc., Vol. 32, No. 1, pp. 94-99, 2000. Cardiac output is directed primarily to skeletal muscle during exercise. Recent investigations have examined how different groups of skeletal muscle compete for the cardiac output during exercise. To date, there is a lack of consistent findings on a blood flow steal effect of arm versus leg exercise, although the majority of data suggest that leg blood flow is not compromised when arm exercise is added to leg exercise. A recent set of experiments have demonstrated that respiratory muscles compete favorably for blood flow with the legs during maximal exercise. Decreased work of breathing leads to: 1) a decrease in cardiac output, due primarily to reduced stroke volume; and 2) increased leg blood flow and leg vascular conductance. An increased work of breathing leads to the converse. Exercise performance may also be affected by the work of breathing during heavy exercise due to redistribution of blood flow between the chest wall and the locomotor muscles. It appears that in contrast to arm exercise, respiratory muscles demand a significant portion of the cardiac output during maximal exercise, and the work of breathing normally experienced during heavy exercise compromises leg blood flow. Key Words: BLOOD FLOW DISTRIBUTION, CARDIAC OUTPUT, RESPIRATORY MUSCLES, MAXIMAL EXERCISE
\end{abstract}

$\mathrm{T}$ The distribution of cardiac output during exercise to specific tissues is generally proportional to the metabolic activity of the tissue. Accordingly, the overwhelming majority of cardiac output during exercise is devoted to the working skeletal muscle. Data by Knight et al. (11) and Poole et al. (18) have demonstrated that up to $80-85 \%$ of the total cardiac output is distributed to the working legs during maximal cycle ergometry exercise. Other tissues such as the heart, brain, skin, and viscera have been shown to demand approximately $3-4 \mathrm{~L} \cdot \mathrm{min}^{-1}$ or $7-10 \%$ of the total cardiac output and are not affected/ compromised either by training or detraining (21). Therefore, because the majority of cardiac output is directed to skeletal muscle, a question that has recently given rise to much discussion and investigation is "how does the body respond to competing groups of skeletal muscle, each demanding a large portion of blood flow, given a finite cardiac output?"

\section{ARM EXERCISE VERSUS LEG EXERCISE}

The effect of skeletal muscle work on cardiac output and its distribution have been recently investigated by examining the effect of the addition of arm exercise to leg exercise. One of the first studies exploring this question was performed by Secher et al. (25), who had subjects perform

0195-9131/00/3201-0094/0

MEDICINE \& SCIENCE IN SPORTS \& EXERCISE ${ }_{\circledast}$

Copyright (C) 2000 by the American College of Sports Medicine

Submitted for publication August 1998.

Accepted for publication February 1999. cycle ergometry work at approximately $50-60 \%$ of $\dot{\mathrm{V}}_{2 \max }$ for $8 \mathrm{~min}$. During this time, cardiac output increased and plateaued at approximately $22 \mathrm{~L} \cdot \mathrm{min}^{-1}, \dot{\mathrm{VO}}_{2}$ at $3 \mathrm{~L} \cdot \mathrm{min}^{-1}$, and leg blood flow at $13 \mathrm{~L} \cdot \mathrm{min}^{-1}$. When arm exercise was then added to the already exercising legs, cardiac output increased $\sim 2 \mathrm{~L} \cdot \mathrm{min}^{-1}$ and $\mathrm{V}_{2}$ increased to $75-80 \%$ of $\dot{\mathrm{V}}{ }_{2 \max }$. However, leg blood flow decreased $\sim 2 \mathrm{~L} \cdot \mathrm{min}^{-1}$. Blood pressure was well maintained throughout exercise; therefore, vasoconstriction had to occur in working muscle to maintain the constant blood pressure. This suggested to these authors the limited capacity of the heart to supply blood flow to both the arms and the legs during exercise. That is, the combined demand of the arms and the legs apparently exceeded the pumping capacity of the heart to supply blood flow.

Several investigators have attempted to replicate these findings of a "steal" effect between the arms and the legs during exercise $(19,20,23)$. In these investigations, also performed during submaximal exercise, increased sympathetic excitation of the leg vasculature occurred, as evidenced from increased norepinephrine (NE) spillover, but reduced leg blood flow did not occur. For example, Richardson et al. (19) had subjects perform single leg knee extensor exercise and examined the effect of adding the arms and the other leg to single leg blood flow. Blood flow to the leg was not reduced, although leg NE spillover increased 3-5 times above resting values. Furthermore, with added arm work to cycle exercise, Richter et al. (20) reported that systemic pressure rose sufficiently to preserve flow to the working limb. Thus, the consensus from these studies is that added working muscle mass (arms) does not influence/compromise blood flow to the exercising lower limbs. Why the lack 
of clear consensus regarding a steal effect of cardiac output during exercise between the arms and the legs among these investigations? These previous studies were all conducted at submaximal whole body exercise intensities (50-80\% $\dot{\mathrm{V}} \mathrm{O}_{2 \max }$ ), where the recruitment of additional muscle mass would require cardiac output and $\mathrm{V}_{2}$ to increase. Leg blood flow in these cases would likely follow the increase in total blood flow and $\mathrm{V}_{2}$. Perhaps clear, consistent demonstration of blood flow redistribution and local vasoconstriction might only occur when muscle mass is added at truly maximal work loads where both cardiac output and the arteriovenous oxygen difference are at maximal levels.

\section{RESPIRATORY MUSCLE WORK EFFECTS ON CARDIAC OUTPUT}

An intriguing possibility that exists in the discussion of competing skeletal muscle beds vying for blood flow during exercise is how well the respiratory muscles compete with locomotor muscles for blood flow. Historically, the influence of respiratory muscle work on the cardiovascular system has been regarded as having a minimal role. However, during strenuous exercise in highly fit humans, when the level of ventilatory requirement is such that severe expiratory flow limitation is realized, the oxygen cost of breathing may approach $15 \%$ of total $\dot{\mathrm{VO}}_{2}$ (1). These peak values of the oxygen cost of exercise hyperpnea at maximal exercise probably represent the upper limit for humans because peak perfusion of limb locomotor muscle has been consistently estimated to be about $80-85 \%$ of cardiac output $(11,18)$, and at least some portion of the remaining total available perfusate must be devoted to nonventilatory functions. Theoretically, the metabolic cost of breathing required by the primary respiratory and stabilizing muscles of the chest wall, plus their demand for perfusion to meet this oxygen cost, could potentially limit the blood flow available for locomotor muscles and thereby limit their work output. Accordingly, it seems reasonable to theorize that respiratory muscles would receive a preferential share of blood flow at the expense of limb locomotor muscles under conditions where total cardiac output was at or near maximal. This postulate requires that vasoconstriction occurs in working limb muscles during strenuous exercise and that there is a redistribution of blood flow to the chest wall.

Recently, a set of experiments has been completed at the University of Wisconsin, under the direction of Dr. Jerome Dempsey, investigating the effect of the respiratory muscle work on cardiac output and its distribution during maximal exercise $(6-8,28)$. These findings have demonstrated a significant effect of respiratory muscle unloading (less than control) via proportional assist ventilation on stroke volume and cardiac output during maximal exercise in the healthy, trained human (7). Reducing the work of breathing below control during maximal exercise led to significant decreases in cardiac output and in $\mathrm{V}_{2}$ due nearly entirely to reduced stroke volume, whereas increasing the work of breathing during maximal exercise had no effect on cardiac output or $\mathrm{V}_{2}$. Figure 1 shows individual absolute values for cardiac
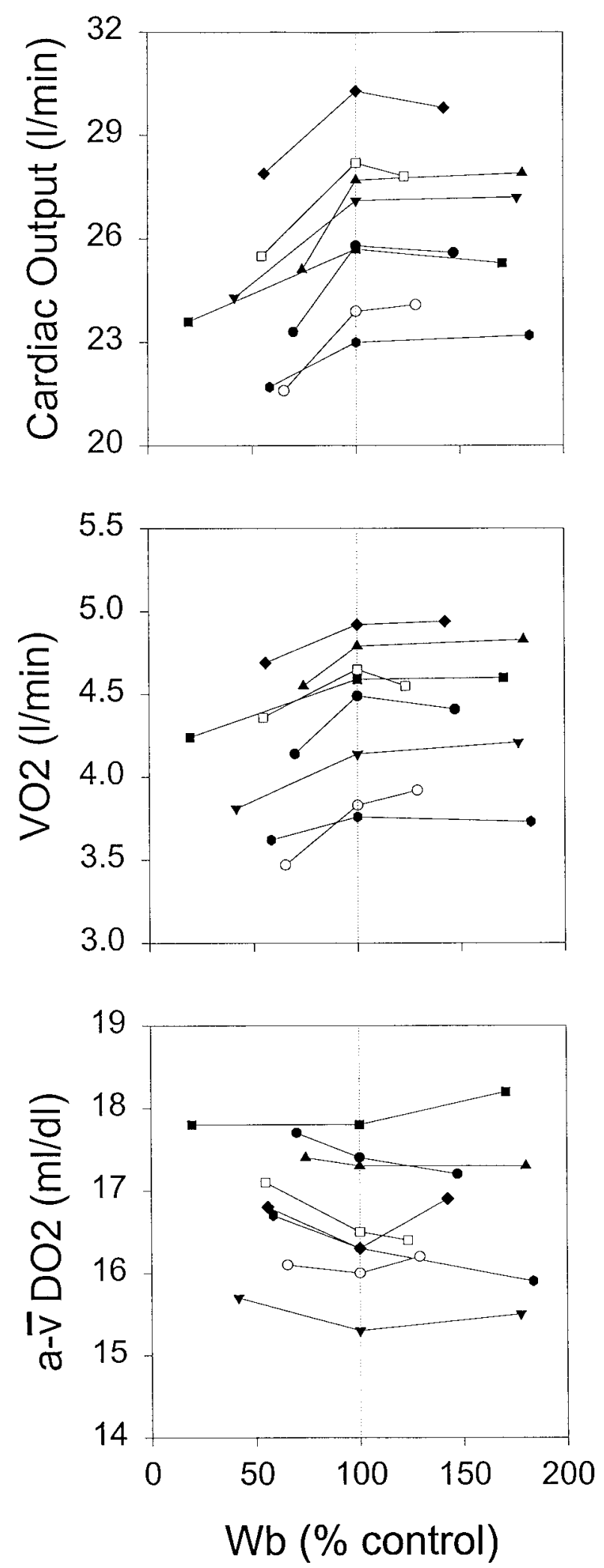

Figure 1-Absolute values of cardiac output, $\dot{\mathrm{V}} \mathrm{O}_{2}$, and a-v̄DO individual subjects across the range of work of breathing $\left(\mathrm{W}_{\mathrm{b}}\right)$ values at $\dot{\mathrm{V}} \mathrm{O}_{2 \max }$. Each symbol represents a different subject $(N=8)$. Data are from Harms et al. (7) with permission.

output, $\dot{\mathrm{VO}}_{2}$, and arteriovenous oxygen difference versus work of breathing obtained during the final 2.5-min measurement period at $\mathrm{V}_{2 \max }$. Without exception, cardiac 

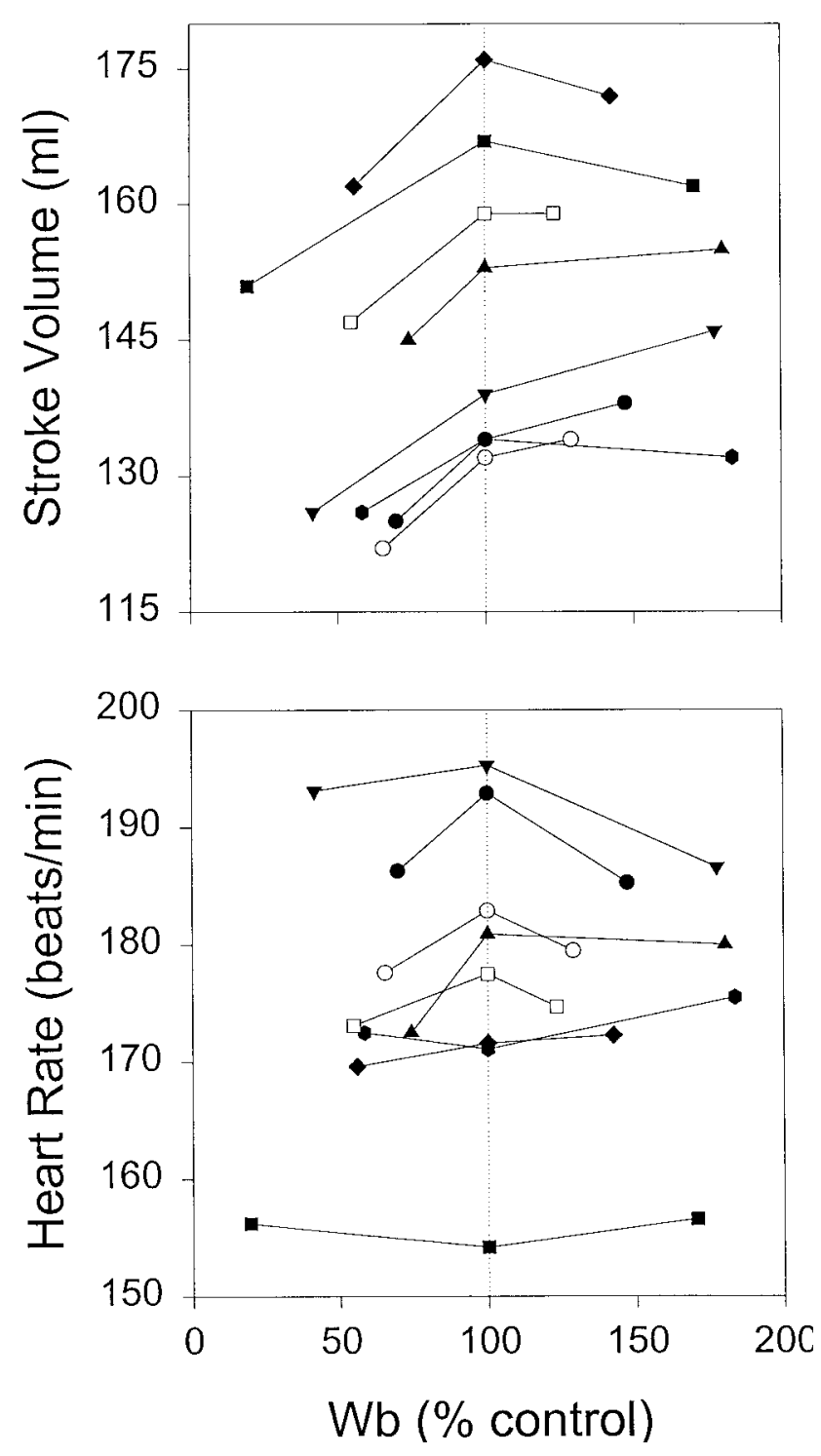

Figure 2-Absolute values of stroke volume and heart rate for individual subjects across the range of work of breathing $\left(W_{b}\right)$ values at $\dot{\mathrm{V}} \mathrm{O}_{2 \max }$ Each symbol represents a different subject $(N=8)$. Data are from Harms et al. (7) with permission.

output and $\dot{\mathrm{VO}}_{2}$ fell with inspiratory muscle unloading but did not change systematically with loading. Figure 2 shows individual values for stroke volume and heart rate with inspiratory muscle unloading, control, and loading. The fall in cardiac output with unloading was due to a fall in stroke volume that occurred in all subjects. Heart rate did not change systematically with respiratory muscle unloading or loading.

What is the mechanism for reduced stroke volume with respiratory muscle unloading during maximal exercise? Correlational analysis implied that the effect of respiratory muscle unloading on cardiac output was attributable to reductions in metabolic demand (i.e., $\mathrm{VO}_{2}$ ) by the respiratory muscles and/or to the effects of an increased (i.e., less negative) intrathoracic pressure on venous return. Table 1 shows the peak inspiratory and expiratory esophageal pressures, cardiac output, stroke volume, and $\mathrm{V}_{2}$ under un- loaded, control, and loaded conditions. First, reduced pleural pressure (compared with control) is seen with unloading. Previous investigations report higher vena cava flow rate during inspiration compared with expiration at both rest and exercise in supine humans (29), as well as reduced stroke volume and cardiac output in healthy humans at rest when intrathoracic pressure was increased via continuous positive airway pressure (CPAP) $(4,16)$. Conversely, the decreased stroke volume with respiratory muscle unloading may be due to reduced metabolic requirement of the respiratory muscles. As shown in Table 1, the decrease in stroke volume (and cardiac output) was associated with a decrease in $\mathrm{V}_{2}$. This apparent dependency of reductions in blood flow on reductions in $\dot{\mathrm{VO}}_{2}$ are consistent with those of Coast et al. (5) and Anholm et al. (3), who increased the work of breathing using resistive loading or hyperpnea in subjects at rest and reported significant increases in heart rate, cardiac output, and in $\dot{\mathrm{VO}}_{2}$. These increases in cardiac output developed slowly (i.e., they required $>20$ s of hyperpnea); therefore, they were attributed to the associated changes in $\dot{\mathrm{VO}}_{2}$. Future research is needed to definitively answer which of these two mechanisms is primary responsible for the decrease in stroke volume with respiratory muscle unloading.

Inspiratory resistive loading at $\dot{\mathrm{V}}_{2 \max }$ did not change stroke volume or cardiac output. This lack of effect of further negativity in pleural pressure during inspiration may mean that the extreme negative pressure incurred during loading was beyond the level at which venous return would be enhanced (24). Alternatively, ventricular expansion during diastole imposed by the pericardium may have simply reached its limit (26). In either case, stroke volume and cardiac output would be independent of further reductions in pleural pressure under control conditions at $\dot{\mathrm{VO}}_{2 \max }$.

\section{RESPIRATORY MUSCLE WORK VERSUS LEG EXERCISE}

What is the effect of respiratory muscle work on leg blood flow? This question was recently addressed by changing the work of breathing, i.e., respiratory muscle loading (increased work of breathing) and unloading (decreased work of breathing) and measured the effect on leg blood flow, measured via the thermodilution technique, and vascular resistance during maximal exercise (6). Increasing the amount of working respiratory muscle mass at maximal exercise at a constant work rate significantly reduced leg

TABLE 1. Effects of respiratory muscle work on cardiac output and $\dot{V}_{2}$ during maximal exercise (see Harms et al. Effects of respiratory muscle work on cardiac output and its distribution during exercise. J. Appl. Physiol. 85:609-618, 1998).

\begin{tabular}{|c|c|c|c|}
\hline & Control & RM Unload & RM Load \\
\hline Peak inspiratory Pes $\left(\mathrm{cm} \mathrm{H}_{2} \mathrm{O}\right)$ & $-27.8 \pm 0.6$ & $-16.3 \pm 0.5^{\star}$ & $-35.6 \pm 0.9^{\star}$ \\
\hline Peak expiratory Pes $\left(\mathrm{cm} \mathrm{H}_{2} \mathrm{O}\right)$ & $22.6 \pm 0.8$ & $17.3 \pm 0.7^{\star}$ & $23.2 \pm 0.6$ \\
\hline Cardiac output $\left(\mathrm{L} \cdot \mathrm{min}^{-1}\right)$ & $26.5 \pm 0.8$ & $24.1 \pm 0.7^{\star}$ & $26.4 \pm 0.8$ \\
\hline Stroke volume $\left(\mathrm{mL}\right.$ beat $\left.^{-1}\right)$ & $149.3 \pm 6.0$ & $138.0 \pm 5.3^{*}$ & $149.8 \pm 5.1$ \\
\hline $\mathrm{VO}_{2}(\mathrm{~L} / \mathrm{min})$ & $4.40 \pm 0.15$ & $4.11 \pm 0.16^{*}$ & $4.40 \pm 0.15$ \\
\hline
\end{tabular}

Values are mean $\pm \mathrm{SE}$.

* Significantly different than control, $P<0.05$

Pes, esophageal pressure. 

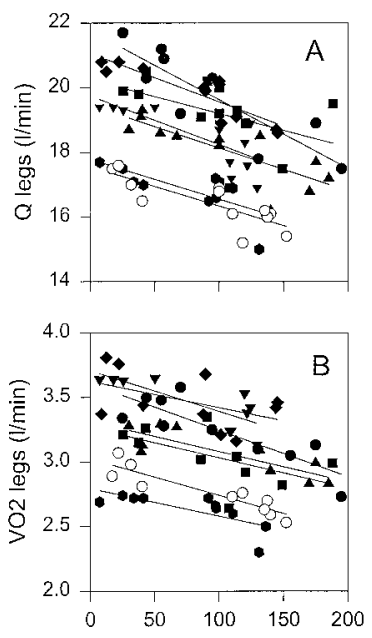

Work of Breathing (\% control)
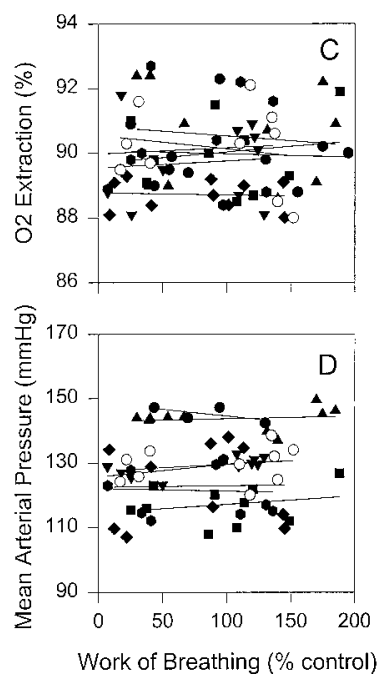

Figure 3-Absolute values for individual subject plots across the range of work of breathing values at $\dot{\mathbf{V}} \mathrm{O}_{2 \mathrm{max}} . \mathbf{A}$, $\dot{\mathrm{Q}}$ legs vs work of breathing (Wb); $\mathrm{B}, \mathrm{VO}_{2}$ legs vs $\mathrm{Wb} ; \mathrm{C}, \mathrm{O}_{2}$ extraction vs $\mathrm{Wb}$; no significant slope across $\mathrm{Wb}$; $\mathrm{D}$, MAP vs Wb; no significant slope across Wb. Symbols represent individual subjects. The difference between each subject's absolute values for Q̇legs and $\dot{V} \mathbf{O}_{2} \operatorname{legs}$ reflect the different absolute max exercise loads. Data are from Harms et al. (6) with permission.

blood flow and $\dot{\mathrm{V}}_{2}$, and increased leg vascular resistance, whereas a decrease in the work of the respiratory muscles increased leg blood flow and $\mathrm{VO}_{2}$, and decreased vascular resistance. Figure 3 shows individual absolute values and each subject's regression for Q $\mathrm{Q}$ egs, $\dot{\mathrm{V}}_{2}$ legs, $\mathrm{O}_{2}$ extraction, and mean arterial pressure (MAP) vs work of breathing. Q with similar slopes with changes in the work of breathing in six of the seven subjects. These findings suggest that respiratory muscles may compete more effectively than limb muscles for total cardiac output during maximal exercise. This possibility is suggested by the increase in diaphragm blood flow and decrease in limb locomotor muscle blood flow during submaximal exercise in rats when the work of breathing was presumably increased via experimental congestive heart failure (15).

If blood flow was indeed redistributed to the legs with respiratory muscle unloading, it seems plausible that the legs should be able to do more work with respiratory muscle unloading. This possibility was recently investigated by having subjects perform repeat 2.5-min cycle ergometry exercise at their $\dot{\mathrm{VO}}_{2 \max }$ work rate and two levels of supramaximal work rates during control or with respiratory muscles unloading (8). Respiratory muscle work increased linearly with exercise work rate during both control and unloaded conditions; but with unloading, respiratory muscle work remained $35-40 \%$ less than control at each work load. With respiratory muscle unloading, $\dot{\mathrm{VO}}_{2}$ was significantly lower than control at $\dot{\mathrm{V}} \mathrm{O}_{2 \max }$ work rate, but as the work rate of the bike was increased with respiratory muscle unloading, $\dot{\mathrm{V}} \mathrm{O}_{2}$ rose back to control $\dot{\mathrm{VO}}_{2 \text { max }}$. This demonstrates that increased power output by the legs at $\mathrm{V}_{2 \max }$ is possible with respiratory muscle unloading. The increased work rate with respiratory muscle unloading was likely due to redistribution of blood flow from the respiratory muscles to the legs, although this has not yet been directly tested.

The substantial redistribution effect between leg and respiratory muscles may reflect two important properties of respiratory muscles. First, the diaphragm and accessory respiratory muscles are of high oxidative capacity; accordingly, their resistance vessels may be especially responsive to local vasodilator influences as shown in the highly trained limb muscle vasculature $(13,14)$. Second, increased work by the respiratory muscles has been shown to promote reflex sympatho-excitation and vasoconstriction of systemic vascular beds (9), similar to the reflex pressor responses attributed to type III and IV afferents from contracting limb muscles (see below; 10,17).

What is the mechanism responsible for blood flow redistribution at maximal exercise between respiratory muscles and locomotor muscles when the work of breathing is altered? The change in vascular resistance and redistribution of blood flow between respiratory and locomotor muscles as the work of breathing changed at maximal exercise was accompanied by changes in NE spillover across the working limb muscle. These findings imply an increased muscle sympathetic nerve activity (MSNA) and vasoconstriction with respiratory muscle loading and reduced MSNA and vasodilation with respiratory muscle unloading (23). The vasodilatory effect in response to respiratory unloading is consistent with the concept that a significant level of sympathetically mediated vasoconstriction is normally present in active limb skeletal muscle at maximal exercise (22). These findings also imply that a significant portion of this vasoconstrictor sympathetic outflow during maximal exercise may emanate from tonically active respiratory muscle chemoreflexes.

Two reflexes might be invoked to explain the changes in sympathetic outflow. First, arterial baroreceptor stimulation may have stimulated reflex sympathetic excitation/withdrawal as changes in the work of breathing caused changes in respiratory muscle perfusion. However, the role of baroreceptor feedback effects on sympathetic efferent activity is difficult to evaluate in these complex conditions of large dynamic changes in intrathoracic pressure during maximal exercise because: 1) there was not even transient changes in systemic blood pressure with loading or unloading; however, aortic arch baroreceptor tissue might undergo deformation even in the absence of changing blood pressure, as shown during lower body negative pressure at rest (27); 2) ventricular mechanoreceptors sensitive to cardiac filling pressures would be influenced by any changes in venous return; and 3) aortic baroreceptors are also affected "directly" by changes in intrathoracic and therefore in aortic transmural pressures (3). The predicted changes in cardiac filling pressure or aortic transmural pressure with respiratory muscle loading/unloading would be in the opposite direction expected to elicit the observed reflex vasoconstriction/vasodilation in limb locomotor muscle. Furthermore, the fact that transient changes in heart rate did not occur with unloading/ loading is also indicative that systemic baroreceptors were not influenced by the respiratory changes. A more likely candidate for mediation of reflex vasoconstriction is the muscle 
Distribution of Cardiac Output at $\mathrm{VO}_{2} \max$

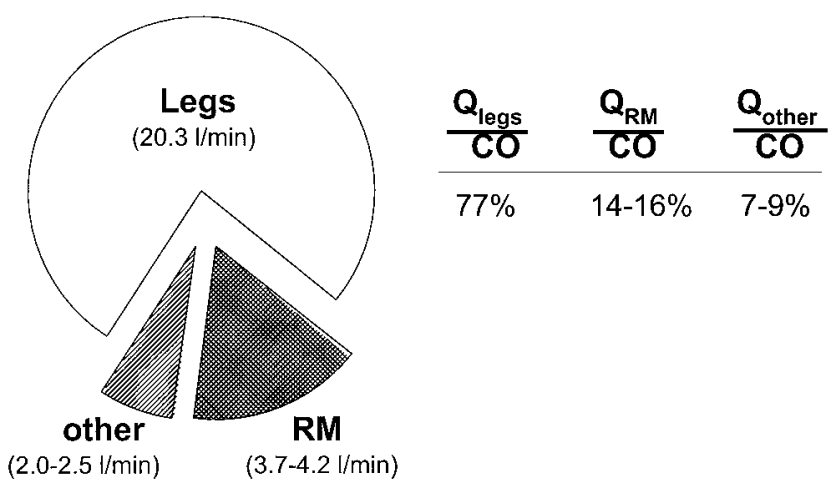

Figure 4-Distribution of total cardiac output between legs, respiratory muscles (RM), and other metabolically active tissues (skin, heart, brain, kidneys, and liver) at $\dot{\mathrm{V}} \mathrm{O}_{2 \text { max }}$. Cardiac output is the mean value measured at $\dot{\mathrm{V}} \mathrm{O}_{2 \max }$, control $\left(26.5 \pm 0.8 \mathrm{~L} \cdot \mathrm{min}^{-1}\right)$. Leg blood flow was also measured under control conditions at $\dot{\mathrm{V}} \mathrm{O}_{2 \max }\left(20.3 \mathrm{~L} \cdot \mathrm{min}^{-1}\right.$; ref 7). Respiratory muscle (RM) blood flow at $\dot{\mathrm{V}} \mathrm{O}_{2 \max }$ was assumed to be equal to the measured fall in $\mathrm{CO}$ obtained with respiratory muscle unloading at $\dot{\mathrm{V}}_{2 \max }$ and extrapolated to zero work of breathing. The range of blood flows shown to RM (14-16\%) and to other nonskeletal muscle tissues (7-9\%) represents values based on our present measurements for RM extrapolated to zero levels for the work of breathing (16\% and $7 \%$ ) and those values, which takes into account the published values for nonskeletal muscle blood flow (14\% and 9\%). Data are from Harms et al. (7) with permission.

chemoreflex, a sensitive feedback mechanism known to originate from Type III and IV afferents in contracting limb muscles (22) and in the diaphragm (9). Upon stimulation of their thin fiber phrenic afferent pathways in the diaphragm, sympatho-excitation and vasoconstriction in both respiratory and resting limb skeletal muscle can be induced (9).

\section{RESPIRATORY MUSCLE WORK AND CARDIOVASCULAR EFFECTS}

The combination of these studies $(6,9)$ demonstrates that the respiratory muscle work experienced under normal physiologic conditions at maximal exercise exerts two types of effects on the cardiovascular response: 1) a substantial portion of the cardiac output (up to $14-16 \%$ ) is directed to the respiratory muscles to support their metabolic requirements, and 2) blood flow is reduced to working locomotor muscles because of sympathetically mediated vasoconstriction induced reflexly and possible originating in contracting respiratory musculature. Figure 4 shows the estimated distribution of total cardiac output to respiratory and to leg locomotor muscles under physiologic control conditions of $\dot{\mathrm{V}} \mathrm{O}_{2 \max }$ as derived from the unloading effects discussed above. The mean value shown for leg blood flow (Q'legs) is the measured value obtained under control conditions at $\dot{\mathrm{VO}}_{2 \max }$ (6). This value is labeled as leg blood flow, but it is not known if this measurement actually includes blood flow to all limb musculature actually involved in the exercise. The value for respiratory muscle blood flow $\left(\dot{Q}_{\mathrm{RM}}\right)$ is taken from the change in cardiac output observed between control conditions and that obtained with unloading and extrapo- lated to zero levels of work of breathing. Note that of the average cardiac output of $26.5 \mathrm{~L} \cdot \mathrm{min}^{-1}, 77 \%$ of this total was directed to the working legs, $14-16 \%$ to the respiratory muscles, and 7-9\% to other metabolically active tissues. Almost identical average values were obtained for the partitioning of total $\dot{\mathrm{VO}}_{2 \max }$ of $4.40 \mathrm{~L} \cdot \mathrm{min}^{-1}$.

\section{RESPIRATORY MUSCLE WORK AND HUMAN PERFORMANCE}

It is not unreasonable to speculate that the demand for oxygen and blood flow by the respiratory muscles during strenuous exercise can affect human performance. Krishnan et al. (12) addressed this theory by having subjects perform constant work exercise at $80 \%$ of $\mathrm{V}_{2 \max }$ during control conditions and with respiratory muscle unloading via proportional assist ventilation. They found that unloading had no effect on ventilation or time to exhaustion despite a marked reduction $(\sim 20-40 \%$ of control) in respiratory muscle load during the exercise. However, Wetter et al. (28) recently reported that time to exhaustion was $\sim 13 \%$ longer with respiratory muscle unloading via proportional assist ventilation and $\sim 12 \%$ shorter with respiratory muscle loading compared with control conditions in six trained subjects cycling at a constant work rate of $90 \% \mathrm{VO}_{2 \max }$. Whole body $\dot{\mathrm{V}} \mathrm{O}_{2}$ was significantly lower than control in the unloaded condition. Increased performance with respiratory muscle unloading is speculated to be due to either blood flow redistribution from the respiratory muscles to working leg muscles or to the reduced whole body $\dot{\mathrm{V}}_{2}$ seen with respiratory muscle unloading. The difference in results among these studies may be due to the intensity of exercise used and in requiring more practice and familiarization sessions with the ventilator in the study by Wetter et al. (28). The increased performance time with respiratory muscle unloading (28) does agree with previous findings using helium:oxygen breathing to unload the respiratory muscles at high exercise intensity (2). Furthermore, the enhanced performance time was associated with reduced $\dot{\mathrm{VO}}_{2}$ during the exercise $(2,28)$, whereas in the study with negative findings, the unloading was not sufficient to cause measurable decreases in $\dot{\mathrm{VO}}_{2}(12)$.

In summary, it appears that in contrast to arm exercise, respiratory muscles demand a significant portion of the cardiac output during maximal exercise. Estimates of blood flow and $\dot{\mathrm{V}}_{2}$ to the respiratory muscles during maximal exercise approximate $14-16 \%$ of the total cardiac output and $\mathrm{V}_{2}$. During maximal exercise, this metabolic demand of the respiratory muscles affects the distribution of cardiac output between the respiratory muscles and the legs such that leg vascular conductance and blood flow increases with respiratory muscle unloading and decreases with respiratory loading. The reflex effects underlying this blood flow redistribution remains unknown; however, these data do clearly support the existence of a significant sympathetic effect output to working skeletal muscle in maximal exercise. Finally, although not yet completely understood or 
investigated, it appears that respiratory muscle work during strenuous exercise affects exercise performance.

My appreciation is extended to Dr. Jerome Dempsey for his guidance and leadership in conducting and developing the majority of the research and concepts discussed. Research was supported

\section{REFERENCES}

1. Aaron, E. A., K. C. Seow, B. D. Johnson, and J. A. Dempsey. Oxygen cost of exercise hyperpnea: implications for performance. J. Appl. Physiol. 72:1818-1825, 1992.

2. Aaron, E. A., K. G. Henke, D. F. Pegelow, and J. A. Dempsey. Effects of mechanical unloading of the respiratory system on exercise and respiratory muscle endurance. Med. Sci. Sports Exerc. 17:290-295, 1985.

3. Anholm, J. D., R. L Johnson, and M. Ramanathan. Changes in cardiac output during sustained maximal ventilation in humans. J. Appl. Physiol. 63:181-187, 1987.

4. Bradley, T. D., R. M. Holloway, R. R. Mclaughlin, B. L. Ross, J. Walters, and P. P. Liu. Cardiac output responses to continuous positive airway pressure in congestive heart failure. Am. Rev. Respir Dis. 145:377-382, 1992.

5. Coast, J. R., R. A. Jensen, S. S. Cassidy, M. Ramanathan, and R. L. JoHnson. Cardiac output and $\mathrm{O}_{2}$ consumption during inspiratory threshold loaded breathing. J. Appl. Physiol. 64:1624-1628, 1988.

6. Harms, C. A., M. A. Babcock, S. R. McClaran, et al. Respiratory muscle work compromises leg blood flow during maximal exercise. J. Appl. Physiol. 82:1573-1583, 1997.

7. Harms, C. A., T. Wetter, S. R. McClaran, et al. Effect of respiratory muscle work on cardiac output and its distribution during maximal exercise. J. Appl. Physiol. 85:609-618, 1998.

8. Harms, C. A., T. Wetter, C. St. Croix, D. F. Pegelow, and J. A. DEMPSEY. Increased power output at $\dot{\mathrm{VO}}_{2 \max }$ with respiratory muscle unloading (Abstract). Med. Sci. Sports Exerc. 30:S41, 1998.

9. Hussain, S., A. Chatillon, A. Comtois, C. Roussos, and S. MagDER. Chemical activation of thin fiber phrenic afferents. 2. Cardiovascular responses. J. Appl. Physiol. 70:77-86, 1991.

10. Kaufman, M. P., and H. V. Forster. Reflexes controlling circulatory, ventilatory and airway responses to exercise. In: Handbook of Physiology-XII-Exercise, L. Rowell and J. Shepard (Eds.). New York: Oxford Press, 1996, pp. 381-442.

11. Knight, D. R., D. C. Poole, W. Schaffartzik, et al. Relationship between body and leg $\mathrm{VO}_{2 \max }$ during maximal cycle ergometry. J. Appl. Physiol. 73:1114-1121, 1992.

12. Krishnan, B., T. Zintel, C. McParland, and C. G. Gallagher. Lack of importance of respiratory muscle load in ventilatory regulation during heavy exercise in humans. J. Physiol. 490:537550, 1996.

13. Laughlin, M. H., R. E. Klabunde, M. D. Delp, and R. B. ArmSTRONG. Effects of dipyridamole on muscle blood flow in exercising miniature swine. Am. J. Physiol. 257(Heart Circ. Physiol. 26):H1507-H1515, 1989.

14. Manohar, M., and A. S. Hassan. The diaphragm does not produce ammonia or lactate during high intensity short-term exercise. Am. J. Physiol. 28(Heart Circ. Physiol. 28):H1185-H1189, 1990.

15. Musch, T. I. Elevated diaphragmatic blood flow during submaximal exercise in rats with chronic heart failure. Am. J. Physiol. 265(Heart Circ. Physiol. 34):H1721-H1726, 1993. by National Heart, Lung, and Blood Institute (NHLBI) grant RO1 HL-15469 (P.I. J. A. Dempsey University of Wisconsin-Madison) and by the Parker B. Francis Foundation Fellowship.

Address for correspondence: Craig A. Harms, Ph.D., Department of Kinesiology, 8 Natatorium, Kansas State University, Manhattan, KS 66506. E-mail: caharms@ksu.edu.

16. Naughton, M. T., M. A. Rahman, K. Hara, J. S. Floras, and T. D. BRADLEY. Effect of continuous positive airway pressure on intrathoracic and left ventricular transmural pressures in patients with congestive heart failure. Circulation 91:1725-1731, 1995.

17. Pickar, J. G., J. R. Hill, and M. P. Kaufman. Dynamic exercise stimulates group III muscle afferents. J. Neurophysiol. 71:753760, 1994.

18. Poole, D. C., G. A. Gaesser, M. C. Hogan, D. R. Knight, and P. D. WAgner. Pulmonary and leg $\mathrm{V}_{2}$ during submaximal exercise: implications for muscular efficiency. J. Appl. Physiol. 72: 805-810, 1992.

19. Richardson R. S., B. Kennedy, D. R. Knight, and P. D. Wagner. High muscle blood flows are not attenuated by recruitment of additional muscle mass. Am. J. Physiol. 269 (Heart Circ. Physiol. 38):C1545-C1552, 1995.

20. Richter, E. A., B. Kiens, M. Hargreaves, and M. Kaejer. Effect of arm cranking on leg blood flow and noradrenaline spillover during leg exercise in man. Acta Physiol. Scand. 144:9-14, 1992.

21. Rowell, L. B. Human Cardiovascular Control. New York: Oxford University Press, 1993, pp. 500-513.

22. Rowell, L. B., and D. S. O'LeAry. Reflex control of the circulation during exercise: chemoreflexes and mechanoreflexes. J. Appl. Physiol. 69:407-418, 1990.

23. Savard, G. K., E. A. Richter, S. Strange, B. Kiens, N. J. Christensen, and B. SAltin. Norepinephrine spillover from skeletal muscle during exercise: role of muscle mass. Am. J. Physiol. 257(Heart Circ. Physiol. 26):H1812-H1818, 1989.

24. Scharf, S. M., R. Brown, K. G. Warner, and S. KhuRi. Intrathoracic pressures and left ventricular configuration with respiratory maneuvers. J. Appl. Physiol. 66:481-491, 1989.

25. Secher, N. H., J. P. Clausen, K. Klausen, I. Noer, and J. TRAP-JENSEN. Central and regional circulatory effects of adding arm exercise to leg exercise. Acta Physiol. Scand. 100:288297, 1977.

26. Stray-Gunderson, J., T. I. Musch, G. C. Haidet, D. P. Swain, G. A. Ordway, and J. H. Mitchell. The effect of pericardectomy on maximal oxygen consumption and maximal cardiac output in untrained dogs. Circ. Res. 58:523-530, 1986.

27. Taylor, J. A., J. R. Halliwill, T. E. Brown, J. Hayano, and D. L. ECKBERG. "Non-hypotensive" hypovolemia reduces ascending aortic dimensions in humans. J. Physiol. 483:289-298, 1995.

28. Wetter, T. J., C. A. Harms, C. St. Croix, D. F. Pegelow, and J. A. DEMPSEY. Effects of respiratory muscle loading and unloading on time to exhaustion during cycle ergometry (Abstract). Med. Sci. Sports Exerc. 30:S190, 1998.

29. Williput, R., C. Rondeux, and A. De Troyer. Breathing affects venous return from legs in humans. J. Appl. Physiol. 57:971-976, 1984. 